\title{
Impact of breast cancer on prospective memory functioning assessed by virtual reality and influence of sleep quality and hormonal therapy: PROSOM-K study
}

Mylène Duivon ${ }^{1}$, Joy Perrier ${ }^{1}$, Florence Joly ${ }^{2,3,4,5}$, Idlir Licaj ${ }^{2,5}$, Jean-Michel Grellard², Bénédicte Clarisse ${ }^{2}$, Christelle Lévy ${ }^{6}$, Philippe Fleury ${ }^{7}$, Sophie Madeleine ${ }^{7}$, Nicolas Lefèvre ${ }^{7}$, Géraldine Rauchs ${ }^{1}$, Grégory Lecouvey ${ }^{1}$, Florence Fraisse ${ }^{1}$, Fausto Viader ${ }^{1,8}$, Francis Eustache ${ }^{1}$, Béatrice Desgranges ${ }^{1}$ and Bénédicte Giffard ${ }^{1,5,9^{*}}$ (D)

\begin{abstract}
Background: Breast cancer $(\mathrm{BC})$ is the most frequent cancer in women with more than $70 \%$ of $\mathrm{BC}$ patients being treated with hormonal therapy $(H T)$. Among these patients, some report difficulties in remembering what they are supposed to do at the right moment, referring to prospective memory (PM). PM is essential for autonomy and medical adherence of patients, and requires an ecological assessment. Virtual reality, that recreates naturalistic environment, seems to be a promising method to evaluate PM. Several BC patients also report sleep disturbances. Given the role of sleep on memory consolidation, it is imperative to explore the influence of sleep quality on PM in $\mathrm{BC}$ patients treated with HT.

The purpose of PROSOM-K study is to assess PM functioning using virtual reality and sleep quality in BC treated or not with HT.

Methods: PROSOM-K is a prospective study including post-menopausal BC patients $\leq 70$ years old treated with radiotherapy $(n=25)$ or with radiotherapy and $\mathrm{HT}(n=25)$, and healthy post-menopausal women $(n=25)$ matched for age and education. PM will be assessed using a virtual reality based task. Other cognitive functions and psychosocial factors will be assessed with validated questionnaires and neuropsychological tests. The study is divided in 3 sessions: a session of familiarisation with the virtual environment and the PM task: a day-time session during which participants learn intentions during the morning and recall them in the evening; and a night-time session during which participants learn intentions in the evening and recall them the following morning. Women will be monitored by wrist actigraphy; during the night-time session, objective sleep quality and quantity will be measured by polysomnography.

Discussion: This is a novel study aiming to assess PM using virtual reality, coupled with the evaluation of other cognitive functions. Polysomnographic study of sleep will provide further information about architectural sleep disturbances in BC. Association between sleep architecture parameters and PM mechanism in BC women treated with $\mathrm{HT}$ will be described in detail. We expect our results will provide knowledge for patients and clinicians and further help to improve patient care and cognitive therapy.
\end{abstract}

Trial registration: NCT03420105, registered: January 10, 2018.

Keywords: Prospective memory, Virtual reality, Sleep quality, Breast cancer, Hormonal therapy

\footnotetext{
* Correspondence: benedicte.giffard@unicaen.fr

${ }^{1}$ Normandie Université, UNICAEN, PSL Université, EPHE, INSERM, U1077, CHU

de Caen, Neuropsychologie et Imagerie de la Mémoire Humaine, 14000

Caen, France

${ }^{5}$ Cancer and Cognition Platform, Ligue Nationale Contre le Cancer, 14076

Caen, France

Full list of author information is available at the end of the article
}

(c) The Author(s). 2018 Open Access This article is distributed under the terms of the Creative Commons Attribution 4.0 International License (http://creativecommons.org/licenses/by/4.0/), which permits unrestricted use, distribution, and

reproduction in any medium, provided you give appropriate credit to the original author(s) and the source, provide a link to the Creative Commons license, and indicate if changes were made. The Creative Commons Public Domain Dedication waiver (http://creativecommons.org/publicdomain/zero/1.0/) applies to the data made available in this article, unless otherwise stated. 


\section{Background}

Breast cancer $(\mathrm{BC})$ is the most frequent cancer in women and its incidence is increasing [1]. Among these patients, some of them experience cognitive troubles and especially difficulties remembering what there are supposed to do at the right time or in the right place $[2,3]$. These memory lapses concern prospective memory (PM) which refers to our ability to remember to accomplish intended tasks or actions at some predefined point in the future.

PM is divided into two components: prospective and retrospective. The first of these refers to the process of remembering that something has to be done at the appropriate time or event, while the second refers to the memory of what has to be done (action). Prospective component gathers two types of intentions: Time-Based (TB) intention referring to self-initiated retrieval of the action after a period of time has elapsed or at a certain time; and Event-Based (EB) intention when an event occurs and triggers the remembering of the action. Intention retrieval relies on two types of processes used in a Dynamic Multiprocess Framework: monitoring and spontaneous retrieval. Their use depends on various factors, for example, characteristics of intentions and ongoing tasks, and importance of realising the action. Monitoring refers to keeping an intention in mind while searching for the prospective component. Spontaneous associative retrieval process relies on automatic processes that bring a retrospective component into mind when a prospective component appears [4]. PM functioning involves various cognitive functions, such as episodic memory, executive functions, and working memory. Retrospective episodic memory is required for the encoding, retention and recall of the intention [5]. Executive functions are involved in planning the intention, inhibiting the ongoing task, and switching to realise the intended action. Working memory is required to keep the intention in mind between the recall and the realisation of the action, and the binding process induces a link between prospective and retrospective components creating a unitary representation of the intention in working memory [6]. PM is essential for daily living tasks and, in BC patients, PM is even more essential for medical adherence, autonomy, and return to social and professional life.

Despite recurrent complaints of patients about their PM, only a few studies have focused on PM deficits in BC [2, 3, 7-10]. Paquet and colleagues used the Memory for Intention Screening Test (MIST) [11], a common PM task, composed of four EB and four TB intentions to retrieve while completing a word puzzle in the laboratory. A naturalistic task had to be carried out at home $24 \mathrm{~h}$ later. The authorsdid not differentiate between EB and TB intentions, but their results revealed decreased performances of patients compared to healthy women [2]. Cheng and colleagues used two laboratory tasks, assessing TB and EB intentions separately. During these tasks, participants had to tap the desk at the target time or event. Results showed a deficit in EB intention retrieval in $\mathrm{BC}$ patients $[3,9,10]$. Altogether, results from these studies revealed an impairment of $\mathrm{PM}$ in $\mathrm{BC}$ patients. However, none distinguished between prospective and retrospective components, which limits the understanding of the impaired processes. In addition to PM, Cheng and colleagues [4-6] assessed general cognitive functioning with Mini Mental State Examination, Verbal Fluency Test, and Digit Span test. Results revealed a significant decrease of cognitive functioning in $\mathrm{BC}$ patients compared with healthy women, but the authors did not correlate neuropsychological scores with PM scores. Cognitive functions known to be involved in PM functioning must be evaluated and correlated with PM scores in order to better understand the PM deficits in BC patients.

Furthermore, laboratory PM tasks lack ecological validity. Virtual reality may be suitable to assess PM because it recreates naturalistic situations of daily life while maintaining experimental rigor [6] that is difficult to uphold in naturalistic PM tasks. Other factors associated with $\mathrm{BC}$ (depression, stress, anxiety, and fatigue) may affect both cognition and PM $[2,12]$, and should therefore be taken into account to deepen knowledge about factors implicated in PM deficits in BC patients.

Studies in BC revealed that $39.5 \%$ to $69 \%$ of patients encounter sleep disturbances, provoked or worsened by cancer and its treatments [13]. The majority of studies used self-report questionnaires and reported sleep disturbances in BC patients. Studies on patients treated for $\mathrm{BC}$ using wrist actigraphy to assess motor activity and sleep quality reported a decreased sleep quality. In cancer patients, very few studies have used polysomnography (PSG), the gold standard of objective assessment of sleep. Although results of sleep architecture (particularly percentages of sleep stages) differ between studies using PSG, they showed a deterioration of sleep quality in $\mathrm{BC}$ patients. Furthermore, one of the parameters of interest, the Slow Waves Sleep (SWS), involved in memory consolidation, seems to be decreased in cancer patients [14-16].

Sleep is well known to play a part on memory consolidation [17-19]. While consolidation of retrospective memories is well studied, few studies have been published on benefits of sleep in PM although mechanisms might be different. Scullin and McDaniel showed that remembering to execute an intention was improved after a $12 \mathrm{~h}$ sleep delay compared to a $12 \mathrm{~h}$ wake delay [19]. Diekelmann and colleagues demonstrated that subjects who slept during the early night (mostly composed of SWS), had better scores at intention execution two days 
later than subjects who had slept during the late night (mostly composed of Rapid Eye Movement sleep) [20]. Sleep, and especially SWS, seems to promote PM consolidation for simple tasks. Results on sleep benefits in more complex and ecological tasks need to be thorough, as well as sleep variables implicated in PM consolidation. In light of SWS involvement in memory consolidation, the link between sleep disturbances and PM deficits in $\mathrm{BC}$ patients need to be explored.

Among factors that may have an impact both on memory and sleep disturbances in BC patients, hormonotherapy seems particularly relevant. The majority of studies assessing impact of treatment on $\mathrm{BC}$ patients have focused on chemotherapy, while up to $70 \%$ of BC patients are treated with hormonal therapy (HT) [21]. Some studies have shown a deleterious impact of HT on patients' cognitive functions, especially memory [22]. Only one study has made an a posteriori analysis about the PM performances at MIST in BC patients treated or not with HT [7]. There were no significant differences between scores of these two groups, probably because components and $\mathrm{EB} / \mathrm{TB}$ intentions were not differentiated. Furthermore, all patients were also treated with chemotherapy, a treatment known to have an impact on cognitive functioning. Thus, this study does not allow for a conclusive understanding of the impact of HT on PM. Few studies have been published about sleep disturbances in BC treated with HT. Additionally, these studies have mostly used self-report questionnaires about sleep quality and results are inconclusive [23]. Some studies reported insomnia complaints from patients treated with HT [24], while others did not [25].

Further studies are, therefore, needed to confirm the impact of HT on PM and sleep in BC patients. This also warrants to implement studies with ecological tasks taking into account the different components of PM coupled with complementary neuropsychological tests to understand processes impaired. Furthermore, no study has assessed the influence of sleep disturbances on PM in $\mathrm{BC}$ patients.

The purpose of PROSOM-K is to evaluate cognitive functions underlying $\mathrm{PM}$ impairment in $\mathrm{BC}$ patients using an ecological task and virtual reality. Further, we aim to assess sleep disturbances encountered by BC women treated or not with $\mathrm{HT}$ and their impact on PM functioning.

\section{Methods}

\section{Study objectives}

The primary objective of the PROSOM-K study is to assess PM performances in $\mathrm{BC}$ patients, in order to determine which components (prospective or retrospective), and types of intentions (EB or $\mathrm{TB}$ ) are the most impaired in $\mathrm{BC}$ patients, and specify which cognitive processes (episodic memory, working memory, or executive functions) are particularly involved in PM decline in BC patients.

The secondary objectives are to:

- clarify the influence of sleep disturbances in $B C$ on PM deficits, using various sleep quality assessments (polysomnography, actigraphy and self-report questionnaires), and by comparing PM scores in two different conditions, depending on the type of delay between encoding and retrieval of intentions: daytime and night-time

- assess the influence of HT on PM functioning by comparing PM scores between BC patients treated with $\mathrm{HT}$ and $\mathrm{BC}$ patients not treated with HT.

\section{Participants}

The PROSOM-K study will include $25 \mathrm{BC}$ patients treated with radiotherapy alone, $25 \mathrm{BC}$ patients treated with radiotherapy and $\mathrm{HT}$, and 25 healthy women. Patients will be recruited in Centre François Baclesse, a regional cancer centre in Caen (Normandy, France). PROSOM-K protocol will be proposed to eligible patients during a follow-up medical care with their oncologist. Healthy volunteer women, matched for age and years of education with $\mathrm{BC}$ patients, will be recruited from our laboratory. Once verified the eligibility criteria (see Table 1) by a physician, each participant will provide her written informed consent to be enrolled in PROSOM-K protocol.

\section{Virtual environment}

The three-dimensional immersive environment has been designed and developed by the Interdisciplinary Centre for Virtual Reality (CIREVE) in Caen (Normandy, France). The environment is a virtual reproduction of the Memorial Museum in Caen. The immersive room (CAVE, Cave Automatic Virtual Environment) is composed of four wide screens for 3D stereoscopic projection: two laterals $(9 \times 3 \mathrm{~m})$, one facial $(4.80 \times 3 \mathrm{~m})$, and one on the floor $(9 \times 4.80 \mathrm{~m})$. Participants will wear stereoscopic glasses with position sensors able to compute perspective in real time. Participants will be placed at the centre of the floor screen [see Additional file 1] and will move using a joystick that also allow them to project the fictional time and a map of the Memorial onto the screen.

\section{PROSOM-K procedure}

Following the phase of inclusion, the experiment is divided into three sequential sessions: session 1 (familiarisation), day-time session, and night-time session [see Additional file 2]. The interval between two consecutive sessions is about one week, and the order 
Table 1 PROSOM-K inclusion and non-inclusion criteria

\begin{tabular}{|c|c|c|}
\hline & Breast cancer patients & Healthy women \\
\hline \multirow[t]{6}{*}{ Inclusion criteria } & \multicolumn{2}{|c|}{1 year post-menopausal } \\
\hline & \multicolumn{2}{|c|}{ Under 70 years of age } \\
\hline & \multicolumn{2}{|c|}{ At least on level 3 (end of primary schools) of the Barbizet scale } \\
\hline & \multicolumn{2}{|c|}{ French native speakers } \\
\hline & $\begin{array}{l}\text { Treated with surgery or radiotherapy for a non- } \\
\text { metastatic breast cancer }\end{array}$ & $\begin{array}{l}\text { Normal cognitive function with the Montreal Cognitive Assessment } \\
\text { (MOCA) score } \geq 26\end{array}$ \\
\hline & $\begin{array}{l}\text { Radiotherapy completed about } 6 \text { months prior to the } \\
\text { study }\end{array}$ & - \\
\hline \multirow{10}{*}{$\begin{array}{l}\text { Non-inclusion } \\
\text { criteria }\end{array}$} & \multicolumn{2}{|c|}{ Neurological sequelae } \\
\hline & \multicolumn{2}{|c|}{ Personality disorders and progressive psychiatric disorder } \\
\hline & \multicolumn{2}{|c|}{ Drug use and/or heavy drinking } \\
\hline & Treated with chemotherapy & $\begin{array}{l}\text { History of cancer, excepting basal-cell carcinoma and carcinoma in situ } \\
\text { of the uterine cervix }\end{array}$ \\
\hline & Patient with a paraneoplastic syndrome & - \\
\hline & Patient unable to perform cognitive tests & - \\
\hline & $\begin{array}{l}\text { Central nervous system primitive tumour or cerebral } \\
\text { metastases }\end{array}$ & - \\
\hline & Primitive cancer different from Breast cancer & - \\
\hline & Metastatic cancer & - \\
\hline & Cognitive disorders pre-existing to cancer diagnosis & - \\
\hline
\end{tabular}

of day-time and night-time sessions is counterbalanced between participants. During each session, participants will have to learn nine intentions and retrieve them in the virtual environment after a delay of $10 \mathrm{~min}$ for session 1 , and about $12 \mathrm{~h}$ for the two other sessions. The lists of 9 intentions are composed of 3 TB intentions (e.g. at 12:11 $\rightarrow$ go to the restaurant for the lunch), 3 linked EB intentions, i.e. with a strong link between the prospective cue and retrospective component (e.g. at the cafeteria $\rightarrow$ buy a black coffee), and 3 no-linked EB intentions (e.g. at the child-care centre $\rightarrow$ ask for a map of the Memorial).

Session 1 allows for the familiarisation of participants with virtual reality use and PM task. This session will be performed either at 8:30 or at 18:30 to assess a potential effect of time on learning and PM performances. A guided-visit of the virtual Memorial Museum will be realised to teach participants how to navigate in the virtual environment, display the time and the map with the joystick, and locate every place and component of the environment. The visit will be followed by a phase of learning the intentions, and after a delay of $10 \mathrm{~min}$, participants will go back to the virtual Memorial to retrieve the intentions.

Day-time session is divided into two parts. The first part will take place at 8:30, subjects will learn new intentions. The second part will take place at 19:00, during which participants will go into the virtual environment and retrieve the intentions.

Night-time session is also divided into two parts. The first part will begin at 17:30, PSG will be placed, and after a meal, women will learn new intentions. Participants will come the next day at 8:30 to have PSG removed, and recall intentions in the virtual Memorial.

\section{PM task}

\section{Learning phase}

The PM task will begin with a phase of intentions learning. Each intention will be displayed during $10 \mathrm{~s}$ on a laptop screen and participants will have to read each of them out loud. Following every three intentions, a cued recall test of these intentions will be realised (e.g. "What will you have to do at 12:11?"). Any unrecalled intentions will be repeated once. After the presentation of all intentions, a cued-recall test will be realised and unrecalled or incorrectly recalled intentions will be repeated. This operation will be done with all unrecalled intentions, until all of them are correctly encoded. Finally, to ensure that all intentions are correctly encoded, they will be retrieved in a last global cued recall test. At the end of this learning phase, participants will have to say how many intentions they think they will remember during the virtual reality task in order to assess their metamnesic awareness. 


\section{Retrieval phase}

After an interval of $10 \mathrm{~min}$ or $12 \mathrm{~h}$, participants will enter the virtual Memorial for the retrieval phase. Intentions will be retrieved during an ongoing task that requires participants to focus their attention on this task and not on the intentions. The ongoing task consists in visiting the Memorial and going to every location indicated by a yellow rectangle on the map, to observe and memorise photographs that they will have to be recognised after the PM task. Every time participants will be in front of a photograph, the yellow rectangle of the emplacement will disappear from the map. Thus, participants will be able to know what photographs remain to be seen.

For TB intentions, a button on the flystick will allow participants to display the hour on the screen. When at a certain time or place, subjects will retrieve an intention, they will have to say out loud what they are supposed to do. Even if the time is up, or if only prospective or retrospective components are retrieved, women will have to express it. Participants will be immersed for about $15 \mathrm{~min}$ in a visit of the Memorial, to view and memorise all photographs and retrieve the intentions.

At the end of the virtual reality task, participants will have to say how many intentions they think they have retrieved, which will allow us to assess their metamemory ability, and a free recall test of all intentions will be realised. For unrecalled intentions, a cued recall test will be done and participants will have to say for EB intentions if they have noticed the prospective component in the environment.

Then participants will realise a recognition task of the photographs seen during the ongoing task. Thirty photographs will be displayed on a laptop screen among which 15 are present in the virtual Memorial. Participants will have to respond "YES" or "NO". The order of the screening of photograph sets is counterbalanced between day-time and night-time sessions, and the total score will be 30 points. Finally, they will complete a debriefing, noting from 0 to 10 the logic of the link between prospective and retrospective components and the importance for them to realise each intention. Indeed, the importance for the participant to realise an intention will influence her motivation and the processes used to retrieve the intention, and thus the probability of realising the intended action.

\section{Outcome measures \\ PM task}

During the learning of each of the 9 intentions ( 3 per type of intention, i.e. 3 linked EB, 3 no-linked EB, and $3 \mathrm{~TB}$ ), a score [0-1] will be attributed per intention for the first cued recall (see Table 2). We will also evaluate the number of repetitions needed to correctly recall all intentions. The maximum total PM encoding score of each session will be 9 points, corresponding to the sum of the points attributed for each intention (1point * 9 intentions).

During the retrieval of the 9 intentions, a score [0-6] will be attributed for each intention corresponding to the points allocated for the prospective component [0-2], the retrospective component [0-2], and the associative component (i.e., the simultaneous retrieval of prospective and retrospective components) [0-2] (see Table 2). The maximum total PM retrieval score of each session will be 54 points, corresponding to the sum of the maximal scores attributed for each intention (6 points * 9 intentions).

\section{Complementary cognitive assessment}

During each session, cognition will be assessed using neuropsychological tests (see Table 3). Global cognitive functioning will be assessed with the Montreal Cognitive Assessment (MoCA) [26], and the crystallised intelligence with the Mill Hill part B [27]. Retrospective episodic memory will be assessed with the French adaptation of Grober and Buschke's procedure [28]. Working memory will be assessed using the Digit Span forward and backward test (Wechsler Adult Intelligence Scale-III [29]), and the binding process will be assessed using a multimodal integration task [30]. During the multimodal integration task, participants have to mentally associate four coloured letters and the location of the cross of the same colour in a grid. Then a grid appears with a black letter, and participants have to indicate if the

Table 2 Scoring of each intention of the PM task LEARNING SCORE [range]

1 point Intention is correctly recalled during the immediate cued recall $[0-1]$

RETRIEVAL SCORES [range]

Prospective [0-2] Retrospective [0-2] Associative [0-2]

2 points Action realised at Retrospective Prospective and the first passage in component is retrospective front of the cue or complete components are at the right time recalled together

1 point Action realised at Retrospective the second passage component is or at $+/-1 \mathrm{~min} \quad$ incomplete (one element is incorrect or forgotten)

0.5 point Action is realised at a subsequent passage or at $+/-2$ min

0 point Action is Retrospective not realised component is not retrieved
Prospective and retrospective components are not recalled together 
letter-location corresponds to the letter-location of the mental association. Executive functioning, especially planning, inhibition, shifting, and updating, which are known to be involved in PM functioning, will be assessed respectively with: the Zoo map test [31], the Stroop [32], the Trail Making Test [33], and the N-back task [34].

\section{Standardised validated self-report questionnaires}

During each session, women will complete self-report questionnaires to assess cognitive functioning and psychosocial factors (see Table 3). Cognitive functioning will also be assessed by self-report questionnaires (Functional Assessment of Cancer Therapy Cognitive Scale: FACT-Cog [35] and Prospective Retrospective Memory Questionnaire: PRMQ [36]).

Self-report questionnaires will be used to assess quality of life (Functional Assessment of Cancer Therapy-General: FACT-G [37]), self-esteem (Questionnaire of Self-Representations [38]), anxiety (State-Trait Anxiety Inventory [39]), depression (Beck Depression Inventory [40]), and fatigue (Multidimensional Fatigue Inventory [41], Functional Assessment of Chronic Illness Therapy-Fatigue: FACIT-F [42]). Scale of fatigue (Visual Analogue Scale to Evaluate Fatigue Severity [43]) and somnolence (Karolinska Sleepiness Scale [44]) will be proposed before the learning phase, as well as before and after the phase of intentions retrieval. Mood will be assessed during each session before intentions retrieval by a self-rating mood scale (the Zerssen Befindlichkeits-Skala [45]). Virtual reality discomfort will be assessed by the simulator sickness questionnaire [46] during each session after the virtual reality based task.

\section{Sleep assessment}

Sleep quality and quantity, circadian typology and insomnia symptoms will be assessed using self-report questionnaires: questionnaire of the past $24 \mathrm{~h}$ (routinely used in our research unit, to assess sleep efficiency and sleep quality of the night before the session of familiarisation), Pittsburgh Sleep Quality Index [47], Insomnia Severity Index [48], and circadian typology (Horne and Ostberg) [49]. Every day between the first and the last sessions, participants will fill out a sleep diary to subjectively assess sleep quality and duration, including hours of bedtime, sleep quality, number and duration of nocturnal awakenings and naps.

During all the protocol, participants will wear an actigraph (MotionWatch 8, camNtech) on their non-dominant wrist. Actigraphy will give information related to sleep/activity rhythm, but also related to sleep quality on a longer duration than PSG (around two weeks). The following variables will be extracted: sleep onset latency, total sleep time, sleep efficiency ([actual sleep time - time in bed] x 100), number of nocturnal awakenings after sleep onset. Finally, it will allow to check whether participants took a nap or not during the day-time session or kept awake during the night-time one.

For the night-time session, sleep of participants will be recorded by ambulatory PSG (the gold standard evaluation of sleep quality) at home, in order to assess sleep onset latency, total sleep time, sleep efficiency, relative percentages of sleep stages, sleep efficiency, number of nocturnal awakenings after sleep onset. Twenty electroencephalography (EEG) electrodes will be placed over the scalp, over prefrontal (FP1/FP2), frontal (F3/F4/F7/ $\mathrm{F} 8 / \mathrm{Fz})$, central $(\mathrm{C} 3 / \mathrm{C} 4 / \mathrm{Cz})$, temporal $(\mathrm{T} 3 / \mathrm{T} 4)$, parietal (P3/P4/Pz), and occipital $(\mathrm{O} 1 / \mathrm{O} 2)$ sites, according to the international 10-20 system; using $\mathrm{Ag} / \mathrm{Au}$ electrodes with a vertex ground and a bi-mastoids reference. The impedance for all electrodes will be kept below $5 \mathrm{k} \Omega$. The hardware EEG filter band pass will be $0.15-121 \mathrm{~Hz}$ and the sample rate will be $256 \mathrm{~Hz}$. Two electrodes will be placed above and under the eyes to record eye movements, as well as two electrodes on the chin to measure muscle tone. An electrocardiogram will also be recorded by placing two electrodes under each clavicle. In order to detect potential sleep apneas or hypopneas, thoracic and abdominal belts will be placed to record respiratory movements, nasal and oral thermistors to measure respiratory airflow and a finger pulse oximeter to measure oxygen saturation. All these sensors will be connected to a Siesta sleep system (Compumedics). Electrodes will be placed by an EEG technician.

\section{Statistical analysis}

This study was designed to control an error risk $\alpha$ of 0.05 and a power of $80 \%$. Assuming cognitive decline for $30 \%$ of BC women under HT versus $10 \%$ among healthy controls [50], the required sample size is 24 patients per group. We thus planned to enrol a total of 75 participants (25 BC patients receiving $\mathrm{HT}, 25 \mathrm{BC}$ patients without indication to HT and 25 healthy women).

Descriptive statistics (relative frequency, mean value and SD) will be estimated for the socio-demographic and clinical variables from the total population included in the study. Comparison of means for sub-groups of participants will be realised by Student's or Wilcoxon's tests as appropriate. Comparisons of the proportions will be performed using both parametric and non-parametric tests. Link between PM and underlying cognitive functions, HT, and sleep quality, will be estimated thanks to univariate and multivariate logistic regression models, and results will be presented with odds ratios (OR) and their 95\% confidence intervals (CI). All analyses will be conducted using R (version 3.4.1).

\section{Discussion}

Numerous BC patients survivors report memory troubles. A recurring complaint is that they forget what they 
Table 3 Neuropsychological tests battery and questionnaires included in the PROSOM-K study, including outcomes measures

\begin{tabular}{|c|c|c|c|}
\hline Domain assessed & Assessments & Outcome measures & Range \\
\hline \multicolumn{4}{|c|}{ Neuropsychological tests } \\
\hline \multirow[t]{2}{*}{ Global functioning } & MOCA [26] & Total number of correct responses & $0-30$ \\
\hline & Mill Hill [27] & Total number of correct responses & $0-34$ \\
\hline \multirow[t]{4}{*}{ Episodic memory } & RL/RI-16 [28] & Immediate free recall score & $0-48$ \\
\hline & & Immediate total recall score & $0-48$ \\
\hline & & Delayed free recall score & $0-16$ \\
\hline & & Delayed total recall score & $0-16$ \\
\hline \multirow[t]{3}{*}{ Working memory } & \multirow{2}{*}{$\begin{array}{l}\text { Digit span forward and } \\
\text { backward [29] }\end{array}$} & Total number of correct trials forward & $0-16$ \\
\hline & & Total number of correct trials backward & $0-16$ \\
\hline & Multimodal integration task [30] & Total number of correct responses & $0-20$ \\
\hline \multirow[t]{5}{*}{ Executive functions } & Zoo map test [31] & Profile score & $0-4$ \\
\hline & Stroop [32] & interference-colour (time) & $\geq 0 \mathrm{~s}$ \\
\hline & TMT [33] & TMT B-TMT A (time) & $\geq 0 \mathrm{~s}$ \\
\hline & & Perseverative errors TMT B (number) & $\geq 0$ \\
\hline & N-back [34] & Total number of correct responses & $0-48$ \\
\hline \multicolumn{4}{|c|}{ Questionnaires } \\
\hline \multirow{3}{*}{$\begin{array}{l}\text { Cognitive self- } \\
\text { assessment }\end{array}$} & Fact-Cog [35] & PCI/PCA/QOL/Oth & $0-72 / 0-28 / 0-16 / 0-16$ \\
\hline & PRMQ [36] & Prospective score & $8-40$ \\
\hline & & Retrospective score & $8-40$ \\
\hline \multirow[t]{2}{*}{ Anxiety } & STAI [39] & State score & $20-80$ \\
\hline & & Trait score & $20-80$ \\
\hline Mood & BfS/BfS' [45] & Total score / Total score & $0-56 / 0-56$ \\
\hline Depression & BDI [40] & Total score & $0-39$ \\
\hline \multirow[t]{2}{*}{ Self-esteem } & QSR [38] & Valence score & $0-100 \%$ \\
\hline & & Certainty score & $0-100 \%$ \\
\hline Quality of life & FACT-G (patients) [37] & Total score & $0-108$ \\
\hline \multirow{4}{*}{$\begin{array}{l}\text { Fatigue and } \\
\text { somnolence }\end{array}$} & VAS-F [43] & Energy score / Fatigue score & $0-50 / 0-130$ \\
\hline & KSS [44] & Total score & $1-9$ \\
\hline & MFI [41] & General fatigue score & $4-20$ \\
\hline & FACIT-F (patients) [42] & Total score & $0-52$ \\
\hline \multirow[t]{4}{*}{ Sleep } & Questionnaire of the past $24 \mathrm{~h}$ & $\begin{array}{l}\text { Sleep efficiency ([total sleep time - total } \\
\text { time in bed] x100) }\end{array}$ & $0-100 \%$ \\
\hline & PSQI [47] & Total score & $0-21$ \\
\hline & ISI [48] & Total score & $0-28$ \\
\hline & Circadian typology (Horne and Ostberg) & Total score & $16-86$ \\
\hline \multirow{2}{*}{$\begin{array}{l}\text { Virtual reality } \\
\text { discomfort }\end{array}$} & Simulator sickness [46] & Nausea score & $0-27$ \\
\hline & & Oculomotor score & $0-21$ \\
\hline
\end{tabular}

MOCA Montreal Cognitive Assessment, RL/RI-16 free recall / cued recall 16 items (French version of the Grober \& Buschke procedure), TMT Trail Making Test, FACTcog Functional Assessment of Cancer Therapy-Cognitive Function, $P C /$ Perceived Cognitive Impairments, PCA Perceived Cognitive Abilities, QOL impact of PCl on Quality Of Life, Oth Others, PRMQ Prospective Retrospective Memory Questionnaire, STAI State-Trait Anxiety Inventory, BfS/BfS' Befindlichkeits-Skala, BDI Beck Depression Inventory, QSR Questionnaire of Self-Representations, FACT-G Functional Assessment of Cancer Therapy-General, VAS- $F$ Visual Analog Scale of Fatigue, KSS Karolinska Sleepiness Scale, MFI Multidimensional Fatigue Inventory, FACIT-F Functional Assessment of Chronic Illness Therapy - Fatigue scale, PSQI Pittsburgh Sleep Quality Index, ISI Insomnia Severity Index 
are supposed to do at the right moment, referring to PM. This PM is essential for self-sufficiency and medical adherence and thus the well-being of $\mathrm{BC}$ patients. Few studies have been published on PM functioning in BC patients, and PM process impairment needs to be more precisely evaluated. Coupled with PM impairment, several BC patients report sleep disturbances. Few studies have used PSG to assess sleep in BC, but results have revealed a decrease of sleep quality in BC patients. Knowing the involvement of sleep in memory consolidation, these results support the necessity to investigate the link between memory impairment and sleep disturbances in BC. Furthermore, HT seems to have a negative impact on memory and sleep, but there is still a lack of research in this area.

The current study will assess PM using an innovating and ecological virtual reality based task. The different types of components and intentions will be distinguished and correlated with performances in various neuropsychological tests. These tests will assess working memory, episodic memory, and executive functions known to be involved in PM functioning. The findings are expected to improve understanding of PM impairment and underlying mechanism in BC patients. Sleep will be assessed by PSG in order to obtain additional information related to sleep architecture. Sleep architecture parameters will also be correlated to PM scores and performances at night-time and day-time sessions will be compared in order to put forward the consolidation of prospective memories during sleep. These various assessments will be performed among $\mathrm{BC}$ patients treated or not with HT and healthy women, so that it will be possible to bring to light the possible specific impact of either $\mathrm{BC}$ and/or HT on PM functioning and sleep quality.

Even though the current study aims at assessing PM using an ecological task in a virtual environment, it remains a limitation. Virtual reality may provoke uncomfortable sensations like nausea and dizziness. Session of familiarisation will allow participants to become accustomed with virtual reality. If at the end of the session 1 , participants are not used to virtual reality and feel sick, the task will be stopped and they will be withdraw from the study.

\section{Conclusion}

The PROSOM-K trial is expected to bring multifaceted information on PM difficulties among BC patients. Indeed, the assessment of the relationship between components and intentions of PM using virtual reality, and neuropsychological tests, should lead to advanced knowledge about the PM processes impaired in $\mathrm{BC}$ patients. PSG data will be an opportunity to better explore the architectural sleep disturbances in BC. Thanks to the three groups of participants and the three sessions, some information should be given on the influence of sleep and $\mathrm{HT}$ on PM functioning. In a longer term, we expect our findings will be useful for patients and clinicians to understand and take into account their complaints, and thereby improve their take care. We also expect our results will further help to develop applications to improve their daily life and compensate for their PM impairment, as well as to improve cognitive therapy related to sleep and cognitive disorders.

\section{Additional files}

Additional file 1: Figure S1. Subject during the PM task, in the immersive room (CIREVE, Caen). (JPG 1015 kb)

Additional file 2: Figure S2. PROSOM-K procedure. (PNG 503 kb)

\section{Abbreviations}

BC: Breast Cancer; EB: Event-Based; HT: Hormonal Therapy; PM: Prospective Memory; PSG: Polysomnography; TB: Time-Based

\section{Acknowledgements}

The authors would like to thank Stéphane Grimaldi, Director-general of the Memorial of Caen for his contribution to the realisation of the virtual museum, and Catharine Mason for reviewing the English style.

\section{Funding}

This work is supported by the Région Normandie (Réseaux d'Intérêts Normands, RIN) and the Cancéropôle Nord Ouest.

\section{Authors' contributions}

$B G, B D, G L, F E$ and $F J$ have devised the study concept and design. MD, JP, $B D$, and $B G$ wrote the manuscript. IL was responsible for overseeing the statistical section. All authors (MD, JP, FJ, IL, JMG, BC, CL, PF, SM, NL, GR, GL, $F F, F V, F E, B D$, and $B G$ ) have contributed to the study protocol, read and approved the final manuscript.

\section{Ethics approval and consent to participate}

This study has received ethical approval from the Comité de Protection des Personnes Ile de France III in November 2017 (N ID-RCB: 2017-A02778-45). All participants will give their informed consent before any study related assessment start.

\section{Consent for publication}

Not applicable.

\section{Competing interests}

The authors declare that they have no competing interests.

\section{Publisher's Note}

Springer Nature remains neutral with regard to jurisdictional claims in published maps and institutional affiliations.

\section{Author details}

${ }^{1}$ Normandie Université, UNICAEN, PSL Université, EPHE, INSERM, U1077, CHU de Caen, Neuropsychologie et Imagerie de la Mémoire Humaine, 14000 Caen, France. ${ }^{2}$ Clinical Research Department, Centre François Baclesse, 14076 Caen, France. ${ }^{3}$ Normandie Université, UNICAEN, INSERM, U1086 ANTICIPE, 14076 Caen, France. ${ }^{4}$ Medical Oncology Department, CHU de Caen, 14000 Caen, France. ${ }^{5}$ Cancer and Cognition Platform, Ligue Nationale Contre le Cancer, 14076 Caen, France. ${ }^{6}$ Medical Oncology Department, Centre François Baclesse, 14076 Caen, France. ${ }^{7}$ Normandie Université, UNICAEN, CIREVE, 14000 Caen, France. ${ }^{8}$ Neurology Department, CHU de Caen, 14000 Caen, France. ${ }^{9}$ Pôle des Formations et de Recherche en Santé, 2 rue des Rochambelles, CS-14032 Caen Cedex, France. 


\section{Received: 15 June 2018 Accepted: 20 August 2018}

\section{Published online: 03 September 2018}

\section{References}

1. Jéhannin-Ligier K, Dantony E, Bossard N, Molinié F, Defossez G, DaubisseMarliac L, et al. Projection de l'incidence et de la mortalité par cancer en France métropolitaine en 2017. In: Rapport technique. Saint-Maurice: Santé publique France; 2017. p. 1-80.

2. Paquet $L$, Collins B, Song X, Chinneck A, Bedard M, Verma S. A pilot study of prospective memory functioning in early breast cancer survivors. Breast. 2013;22:455-61.

3. Cheng H, Yang Z, Dong B, Chen C, Zhang M, Huang Z, et al. Chemotherapy-induced prospective memory impairment in patients with breast cancer. Psychooncology. 2013;96:1-4. https://doi.org/10.1002/pon.3291.

4. Scullin MK, McDaniel MA, Shelton JT. The dynamic multiprocess framework: evidence from prospective memory with contextual variability. Cogn Psychol. 2013;67:55-71. https://doi.org/10.1016/j.cogpsych.2013.07.001.

5. Kliegel M, Eschen A, Thöne-Otto AIT. Planning and realization of complex intentions in traumatic brain injury and normal aging. Brain Cogn. 2004; 56:43-54.

6. Lecouvey G, Gonneaud J, Piolino P, Madeleine S, Orriols E, Fleury P, et al. Is binding decline the main source of the ageing effect on prospective memory? A ride in a virtual town. Socioaffective Neurosci Psychol. 2017;7 https://doi.org/10.1080/20009011.2017.1304610.

7. Bedard M, Verma S, Collins B, Song X, Paquet L. Prospective memory impairment in chemotherapy-exposed early breast cancer survivors: preliminary evidence from a clinical test. J Psychosoc Oncol. 2016;34:291304. https://doi.org/10.1080/07347332.2016.1181133.

8. Paquet L, Verma S, Collins B, Chinneck A, Bedard M, Song X. Testing a novel account of the dissociation between self-reported memory problems and memory performance in chemotherapy-treated breast cancer survivors. Psychooncology. 2018;27:171-7. https://doi.org/10.1002/pon.4389.

9. Cheng H, Li W, Gong L, Xuan H, Huang Z, Zhao H, et al. Altered restingstate hippocampal functional networks associated with chemotherapyinduced prospective memory impairment in breast cancer survivors. Sci Rep. 2017;7:45135. https://doi.org/10.1038/srep45135.

10. Li W, Gan C, LV Y, Wang S, Cheng H. Chemotherapy-induced prospective memory impairment in breast cancer patients with different hormone receptor expression. Medicine (Baltimore). 2017;96:e6514. https://doi.org/10. 1097/MD.0000000000006514.

11. Raskin SA. Memory for intentions screening test: psychometric properties and clinical evidence. Brain Impair. 2009;10:23-33. https://doi.org/10.1375/ brim.10.1.23.

12. Joly F, Giffard B, Rigal O, De Ruiter MB, Small BJ, Dubois M, et al. Impact of Cancer and its treatments on cognitive function: advances in research from the Paris international cognition and Cancer task force symposium and update since 2012. J Pain Symptom Manag. 2015;50:830-41.

13. Chen D, Yin Z, Fang B. Measurements and status of sleep quality in patients with cancers. Support Care Cancer. 2018;26:405-14.

14. Roscoe JA, Perlis ML, Pigeon WR, O'Neill KH, Heckler CE, Matteson-Rusby SE, et al. Few changes observed in polysomnographic-assessed sleep before and after completion of chemotherapy. J Psychosom Res. 2011;71:423-8.

15. Aldridge-Gerry A, Zeitzer J, Palesh OG, Jo B, Nouriani B, Neri E, et al. Psychosocial correlates of sleep quality and architecture in women with metastatic breast cancer. Sleep Med. 2013;14:1-18.

16. Parker KP, Bliwise DL, Ribeiro M, Jain SR, Vena Cl, Kohles-Baker MK, et al. Sleep/wake patterns of individuals with advanced cancer measured by ambulatory polysomnography. J Clin Oncol. 2008;26:2464-72.

17. Rasch B, Born J. About sleep's role in memory. Physiol Rev. 2013;93:681-766. https://doi.org/10.1152/physrev.00032.2012.

18. Harand C, Bertran F, Doidy F, Guénolé F, Desgranges B, Eustache F, et al. How aging affects sleep-dependent memory consolidation? Front Neurol. 2012;3:1-6.

19. Scullin MK, McDaniel MA. Remembering to execute a goal: sleep on it! Psychol Sci. 2010;21:1028-35. https://doi.org/10.1177/0956797610373373.

20. Diekelmann S, Wilhelm I, Wagner U, Born J. Sleep to implement an intention. Sleep. 2013;36:149-53. https://doi.org/10.5665/sleep.2322.

21. Bender CM, Merriman JD, Gentry AL, Ahrendt GM, Berga SL, Brufsky AM, et al. Patterns of change in cognitive function with anastrozole therapy. Cancer. 2015;121:2627-36.
22. Underwood EA, Rochon PA, Moineddin R, Lee PE, Wu W, Pritchard Kl, et al. Cognitive sequelae of endocrine therapy in women treated for breast cancer: a meta-analysis. Breast Cancer Res Treat. 2018;168:299-310. https:// doi.org/10.1007/s10549-017-4627-4.

23. Costa AR, Fontes F, Pereira S, Gonçalves M, Azevedo A, Lunet N. Impact of breast cancer treatments on sleep disturbances - a systematic review. Breast. 2014;23:697-709. https://doi.org/10.1016/j.breast.2014.09.003.

24. Desai K, Mao JJ, Su I, DeMichele A, Li Q, Xie SX, et al. Prevalence and risk factors for insomnia among breast cancer patients on aromatase inhibitors. Support Care Cancer. 2013;21:43-51.

25. Savard J, Ivers H, Savard MH, Morin CM. Cancer treatments and their side effects are associated with aggravation of insomnia: results of a longitudinal study. Cancer. 2015:121:1703-11.

26. Nasreddine Z, Charbonneau S, Cummings JL. The Montreal cognitive assessment, MoCA: a brief screening tool for mild cognitive impairment. J Am Geriatr Soc. 2005;53:695-9.

27. Deltour JJ. Echelle de vocabulaire de Mill Hill de JC Raven. In: Adapt française normes Eur du Mill Hill du Stand Progress Matrices Raven (PM38) Braine-le-Château Ed l'application des Tech Mod; 1993.

28. Van der Linden M, Coyette F, Poitrenaud J, Kalafat M, Calicis F, Wyns C, et al. L'épreuve de rappel libre / rappel indice à 16 items (RL/RI-16). In: L'Évaluation des Troubles de la Mémoire: Présentation de Quatre Tests de Mémoire Épisodique Avec Leur Étalonnage; 2004. p. 25-47.

29. Wechsler D. Wechsler memory scale (WMS-III). San Antonio, TX Psychol Corp 1997;14.

30. Quinette P, Guillery-Girard B, Hainselin M, Laisney M, Desgranges B, Eustache F. Évaluation du buffer épisodique: deux épreuves testant les capacités d'association et de stockage d'informations verbales et spatiales. Rev Neuropsychol. 2013;5:56-62.

31. Allain P, Nicoleau S, Pinon K, Etcharry-Bouyx F, Barré J, Berrut G, et al. Executive functioning in normal aging: a study of action planning using the zoo map test. Brain Cogn. 2005:57:4-7.

32. Stroop J. Studies of interference in serial verbal reactions. J Exp Psychol. 1935;18:643.

33. Reitan RM. Validity of the trail making test as an indication of organic brain damage. Percept Mot Skills. 1958:8:271-86.

34. Gevins A, Cutillo B. Neuroelectric evidence for distributed processing in human working memory. Electroencephalogr Clin Neurophysiol. 1993;87: 128-43.

35. Joly F, Lange M, Rigal O, Correia H, Giffard B, Beaumont JL, et al. French version of the functional assessment of Cancer therapy-cognitive function (FACT-Cog) version 3. Support Care Cancer. 2012;20:3297-305.

36. Smith G, Del Sala S, Logie RH, Maylor EA. Prospective and retrospective memory in normal ageing and dementia: a questionnaire study. Memory. 2000;8:311-21.

37. Cella DF, Tulsky DS, Gray G, Sarafian B, Linn E, Bonomi A, et al. The functional assessment of cancer therapy scale: development and validation of the general measure. J Clin Oncol. 1993;11:570-9.

38. Duval C, Desgranges B, de La Sayette V, Belliard S, Eustache F, Piolino P. What happens to personal identity when semantic knowledge degrades? A study of the self and autobiographical memory in semantic dementia. Neuropsychologia. 2012;50:254-65. https://doi.org/10.1016/j. neuropsychologia.2011.11.019.

39. Spielberger SD. Manual for the state-trait anxiety inventory (STAI). Palo Alto: CA Consult Psychol Press; 1983.

40. Beck A, Ward C, Mendelson M, Mock J, Erbaugh J. An inventory for measuring depression. Arch Gen Psychiatry. 1961;4:561-71.

41. Smets EM, Garssen B, Bonke B, De Haes JC. The multidimensional fatigue inventory (MFI) psychometric qualities of an instrument to assess fatigue. J Psychosom Res. 1995;39:315-25.

42. Yellen S, Cella D, Webster K, Blendowski C, Kaplan E. Measuring fatigue and other anemia-related symptoms with the functional assessment of cancer therapy (FACT) measurement system. J Pain Symptom Manag. 1997;13:63-74.

43. Lee K, Hicks G, Nino-Murcia G. Validity and reliability of a scale to assess fatigue. Psychiatry Res. 1991;36:291-8.

44. Akerstedt T, Gillberg M. Subjective and objective sleepiness in the active individual. Int J Neurosci. 1990:52:29-37.

45. Bobon D, Lapierre $Y$, Lottin T. Validity and sensitivity of the French version of the Zerssen BfS/BfS' self rating mood scale during treatment with trazodone and amitriptyline. Prog Neuropsychopharmacol. 1981;5:519-22. 
46. Kennedy RS, Lane NE, Berbaum KS, Lilienthal MG. Simulator sickness questionnaire: an enhanced method for quantifying simulator sickness. Int J Aviat Psychol. 1993;3:203-20.

47. Buysse DJ, Reynolds III CF, Monk TH, Berman SR, Kupfer DJ. The Pittsburgh sleep quality index: a new instrument for psychiatric practice and research. Psychiatry Res. 1989;28:193-213. https://doi.org/10.1016/01651781(89)90047-4 .

48. Morin $\mathrm{CM}$, Belleville $\mathrm{G}$, Bélanger $\mathrm{L}$, Ivers $\mathrm{H}$. The insomnia severity index: psychometric indicators to detect insomnia cases and evaluate treatment response. Sleep. 2011;34:601-8.

49. Horne JA, Ostberg O. A self-assessment questionnaire to determine morning-eveningness in human circadian rythms. Int J Chronobiol. 1976;4: 97-110.

50. Collins B, Mackenzie J, Stewart A, Bielajew C, Verma S. Cognitive effects of hormonal therapy in early stage breast cancer patients: a prospective study. Psychooncology. 2009;18:811-21. https://doi.org/10.1002/pon.1453.

Ready to submit your research? Choose BMC and benefit from:

- fast, convenient online submission

- thorough peer review by experienced researchers in your field

- rapid publication on acceptance

- support for research data, including large and complex data types

- gold Open Access which fosters wider collaboration and increased citations

- maximum visibility for your research: over $100 \mathrm{M}$ website views per year

At $\mathrm{BMC}$, research is always in progress.

Learn more biomedcentral.com/submissions 